\title{
Purification, Preliminary Structural Characterization, and In Vitro Inhibitory Effect on Digestive Enzymes by $\beta$-Glucan from Qingke (Tibetan Hulless Barley)
}

\author{
Jialiang Hu, ${ }^{1}$ Yue Wu, ${ }^{2}$ Huifang Xie ${ }^{D},{ }^{3}$ Wanyin Shi, ${ }^{2}$ Zhiyuan Chen, ${ }^{4}$ Dan Jiang, ${ }^{4}$ Hui Hu, \\ Xiangwei Zheng $\mathbb{D}^{1},{ }^{1}$ Jian $X u \mathbb{D}^{2},{ }^{2}$ Yuejun Yang $\mathbb{D}^{2}$, and Yuancai Liu $\mathbb{D}^{2}$ \\ ${ }^{1}$ Shanghai University of Traditional Chinese Medicine Engineering Research Center of Modern Preparation Technology of TCM, \\ Ministry of Education, China \\ ${ }^{2}$ Hubei Provincial Key Laboratory for Quality and Safety of Traditional Chinese Medicine Health Food, Jing Brand \\ Research Institute, Jing Brand Co. Ltd., China \\ ${ }^{3}$ Biotechnology Research \& Innovation Department, Shanghai Huangdian Investment Co., Ltd, China \\ ${ }^{4}$ Jing Brand Chizhengtang Pharmaceutical Co., Ltd., China \\ ${ }^{5}$ Hubei Provincial Traditional Chinese Medicine Formula Granule Engineering Technology Research Center, Huangshi, China
}

Correspondence should be addressed to Xiangwei Zheng; zhengxwsh@hotmail.com, Jian Xu; xujian@jingpai.com, Yuejun Yang; yyj@jingpai.com, and Yuancai Liu; lyc@jingpai.com

Jialiang $\mathrm{Hu}$, Yue $\mathrm{Wu}$, and Huifang Xie contributed equally to this work.

Received 11 January 2020; Revised 31 March 2020; Accepted 22 April 2020; Published 19 May 2020

Guest Editor: Yu Tao

Copyright (c) 2020 Jialiang $\mathrm{Hu}$ et al. This is an open access article distributed under the Creative Commons Attribution License, which permits unrestricted use, distribution, and reproduction in any medium, provided the original work is properly cited.

\begin{abstract}
Background and Objective. Qingke (Tibetan hulless barley, Hordeum vulgare L.) contains a high content of $\beta$-glucan among all the cereal varieties. Although $\beta$-glucan has multiple physiological functions, the physiological function of qingke $\beta$-glucan was few studied. In this study, the $\beta$-glucan was isolated, purified, determined the structural characterization, and measured the inhibitory activity to enzymes correlating blood sugar and lipid. Methods. $\beta$-Glucan was isolated from enzymatic aqueous extract of qingke by using deproteinization, decolorization, DEAE-52 column chromatography, and sepharose CL-4B agarose gel column chromatography. The structure of the $\beta$-glucan was determined using FT-IR and ${ }^{13} \mathrm{C}-\mathrm{NMR}$ spectra analysis, and molecular mass by use of HPSEC-dRI-LS. The kinematic viscosity was measured. The inhibitory effects of this $\beta$-glucan on four enzymes were investigated. Results. This $\beta$-glucan had a uniform molecular weight of $201,000 \mathrm{Da}$ with $\beta$-(1 $\longrightarrow 4)$ as the main chain and $\beta-(1 \longrightarrow 3)$ as a side chain. The $\beta$-glucan presented a relatively strong inhibitory activity on $\alpha$-glucosidase, moderate inhibition on invertase, and a weak inhibition on $\alpha$-amylase, whereas it did not inhibit lipase. Conclusion. The study indicates that the enzymatic $\beta$-glucan from qingke has the potential as natural auxiliary hypoglycemic additives in functional medicine or foods.
\end{abstract}

\section{Introduction}

Hull-less barley is a kind of cultivated barley variety widely spreading over highland areas throughout the world. As the husk covering the palea and lemma is fell off during the harvest, it is also known as naked barley. Hull-less barley is the main grain source for the local population in cold regions such as countries in the Himalayas and North Africa [1].
Qingke (Tibetan hulless barley, Hordeum vulgare L.) is one of the hull-less barleys that distributes in the highland areas of China (Qinghai-Tibet plateau, Yunnan and Sichuan province). Over the past decade, it is gradually becoming to notice that qingke is healthy and can be used as a functional food.

It is prominent that qingke has a high content of $\beta$-glucan in cereal crops $[2,3]$. $\beta$-Glucan of qingke is an unbranched polysaccharides consisting of $\beta$-D- 


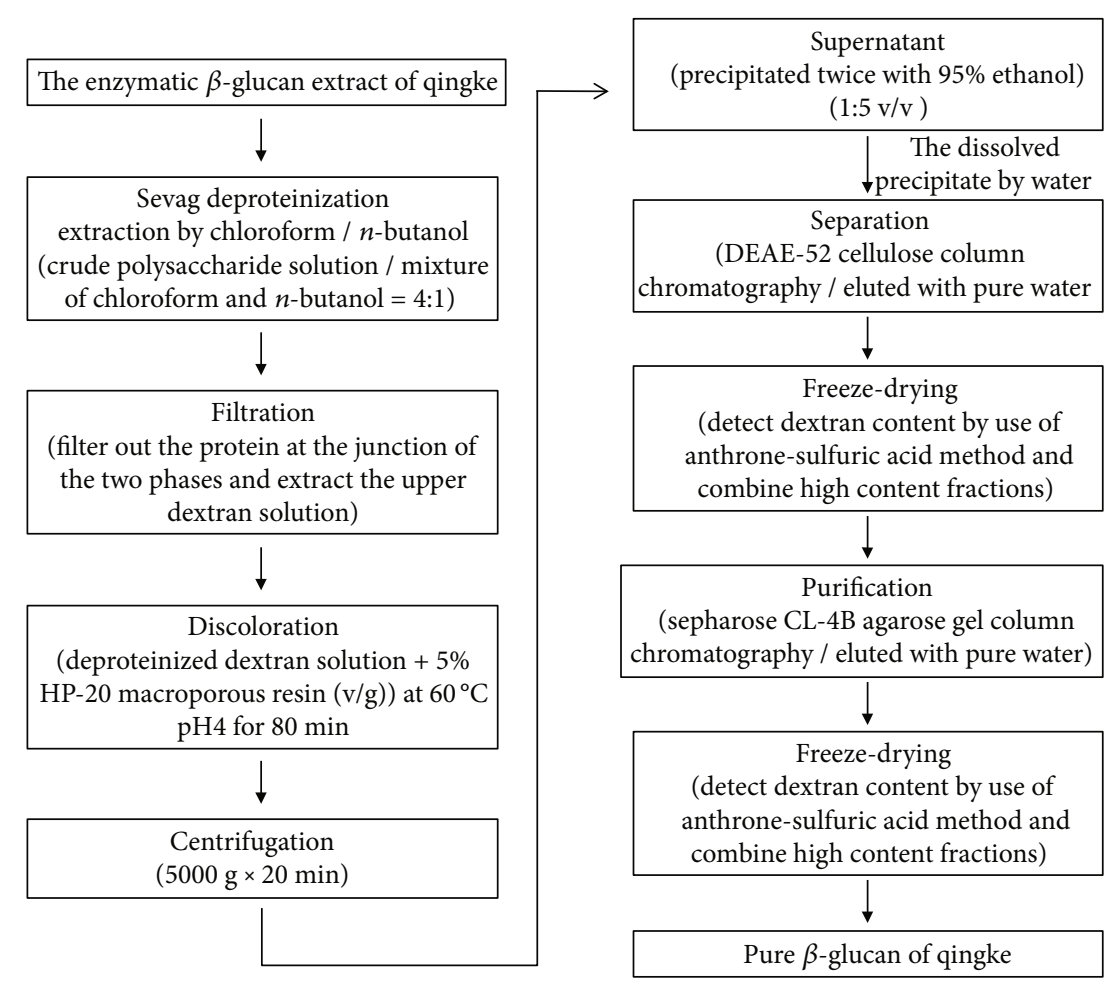

FIgURE 1: Extraction-purification scheme of $\beta$-glucan prepared from qingke (Tibetan Hulless Barley).

glucopyranose units linked through $(1 \longrightarrow 4,1 \longrightarrow 3)$ glycosidic bonds. The cereal $\beta$-glucan is a kind of dietary fiber that supports plant cell wall and possesses a number of functionalities, which include lowering blood cholesterol level, decreasing insulin level, and attenuating postprandial blood sugar $[4,5]$. The $\beta$-glucan of qingke has been studied to show some activities in vivo and in vitro. The $\beta$-glucan extract from qingke showed obviously prebiotic characteristics [6]. It could effectively reduce the risk of arterial sclerosis via decreasing the serum glucose, serum lipid, and insulin resistance [7]. The enzymatic $\beta$-glucan extract of qingke has auxiliary hypoglycemic function on mice [8]. The chemical modification of purified $\beta$-glucan is helpful for improving the inhibition of the lipase in vitro, as published by Guo et al. [9-11]. However, up to now, no systematic study has been done on the activities of the purified $\beta$-glucan from qingke on the direct inhibitory activity against glycosidases relating to serum glucose. The glycosidases, such as $\alpha$-glucosidase, $\alpha$-amylase, and invertase, can hydrolyze polysaccharides to increase the blood sugar [12]. The inhibition to the digestive enzymes (glycosidases and lipase) might contribute to the health caring and therapy for hyperglycemia and hyperlipidemia. In our previous studies, qingke $\beta$-glucan was enzymatically extracted with the aim of broadening its application [8]. And the biological activity of the enzymatic $\beta$-glucan was not investigated. In this study, we set out to separate and purify the enzymatic $\beta$-glucan from qingke, then to explore the structural characterization and bio-activities, of the purified $\beta$-glucan, on digestive enzymes accounting for increasing glucose and lipid. It may be helpful to expand the application of qingke $\beta$-glucan.

\section{Materials and Methods}

2.1. Materials and Reagents. The enzymatic $\beta$-glucan crude extract of qingke was obtained from Jing Brand Chizhengtang Pharmaceutical Co., Ltd. All the chemical reagents were analytical grade and purchased from Sinopharm Group Co. Ltd (China). $\alpha$-Amylase (EC number 3.2.1.1), invertase (EC number 3.2.1.26), and $\alpha$-glucosidase (EC number 3.2.1.20) were purchased from Sigma (USA) with the catalog number of A3176, I4504, and G5003, respectively. The lipase (CAS number 9001-62-1) was purchased from Sinopharm Group Co. Ltd. with a catalog number of 64005761 . The positive compound of acarbose was purchased from the BAYER (Germany). The compound of orlistat (catalog number O4139), p-nitrophenyl glucopyranoside (catalog number 877250), and $p$-nitrophenol (catalog number N2752) were purchased from Sigma. The soluble starch (catalog number 10021318), sucrose (catalog number 10021487), and 3,5dinitrosalicylic acid (catalog number 30073424) were purchased from Sinopharm Group Co. Ltd.

2.2. Isolation and Purification of $\beta$-Glucan from Qingke. The enzymatic $\beta$-glucan crude extract of qingke was prepared as described previously [8]. The subsequent separation and purification process referred literature method $[13,14]$ and included four main steps: deproteinization, decolorization, DEAE-52 column chromatography, and sepharose CL-4B agarose gel column chromatography (Figure 1). Chloroform and $n$-butanol were mixed with a volume ratio of $4: 1$. Then the mixture was added into the enzymatic $\beta$-glucan solution with a volume ratio of $1: 4$, followed with shaking vigorously 
for $20 \mathrm{~min}$ and centrifugation. The denatured protein layer at the junction of the aqueous phase and the organic phase was removed by filtration. The upper aqueous solution was mixed with HP-20 macroporous resin in the ratio of $20: 1(\mathrm{v} / \mathrm{g})$, followed with stirring evenly, $\mathrm{pH}$ adjustment to 4.0, and then standing for $80 \mathrm{~min}$ at $60^{\circ} \mathrm{C}$. The mixture was centrifuged to collect the supernatant for $20 \mathrm{~min}$ at $5000 \mathrm{r} / \mathrm{min}$ to obtain the decolored $\beta$-glucan solution. The supernatant was added with 5 times volume of $95 \%$ ethanol for precipitation overnight and then was centrifuged for $20 \mathrm{~min}$ at $9000 \mathrm{r} / \mathrm{min}$ to collect the precipitate. The precipitation and centrifugation were repeated twice. The dissolved precipitated by water was eluted using DEAE- 52 cellulose column chromatography with pure water. Throughout the elution, the UV detector (SPD-10A, Shimadzu, Japan) connecting with the fraction collector was used to detect the protein profile of the eluent at $280 \mathrm{~nm}$ wavelength. The sugar concentrations of the eluent in each tube were measured by the anthrone-sulfuric acid method at $620 \mathrm{~nm}$ wavelength [15]. The main sugar-containing fractions of the eluent were harvested, combined, and lyophilized by freeze-drying. The redissolved sugar-containing fraction was then purified by sepharose CL-4B agarose gel column chromatography and eluted with pure water. The eluents were measured by the anthrone-sulfuric acid method at $620 \mathrm{~nm}$ wavelength to track the sugar concentrations. Then, the sugar-containing fractions were also harvested, combined, and lyophilized by freeze-drying to obtain the purified enzymatic $\beta$-glucan from qingke (EGQK).

2.3. Viscosity. EGQK solution was prepared by dispersing the $\mathrm{EGQK}$ in deionized water at a concentration of $0.1 \%$. Then, the Ubbelohde capillary viscosimeter was used to determine the kinematic viscosity $(v)$ based on a previously reported method [16]. Time of suspension flow was taken from 5 measurements as average, and the kinematic viscosity was calculated from the equation:

$$
\begin{aligned}
& \text { Kinematic viscosity }\left(\mathrm{mm}^{2} \cdot \mathrm{sec}^{-1}\right) \\
& =\text { capillary constant }\left(\mathrm{mm}^{2} \cdot \mathrm{sec}^{-2}\right) \\
& \quad \times \text { average flow time }(\mathrm{sec})
\end{aligned}
$$

2.4. Molecular Mass Analysis of EGQK. The molecular weight distribution of EGQK was obtained on high-performance size-exclusion chromatography (HPSEC) using the column (Shodex SB-803 HQ, Showa Denko K.K., Japan) [17]. Samples were filtered through a syringe filter $(0.45 \mu \mathrm{m}$ pore $)$, and $20 \mu \mathrm{l}$ filtrate was injected into the HPSEC column. The column was eluted with $0.15 \mathrm{M} \mathrm{NaNO}_{3}$ with a flow rate of $0.6 \mathrm{ml} / \mathrm{min}$, with a laser scattering detector (Wyatt dawn heleos-II, Wyatt DAWN Technology, USA) (LS) and refractive index detector (Optilab T-rEX, Wyatt DAWN Technology, USA) (dRI).

2.5. Fourier-Transform Infrared Spectroscopy (FT-IR) Spectrum of EGQK Analysis. The FT-IR spectrum of EGQK was recorded on a Bruker Vector 22 spectrometer (Bruker Optik GmbH, Germany) using $\mathrm{KBr}$ pellets.
2.6. ${ }^{13} \mathrm{C}-\mathrm{NMR}$ Spectrum Analysis of the Monosaccharide Composition of EGQK. The sample of EGQK $(30 \mathrm{mg})$ was dissolved in $1.0 \mathrm{ml} \mathrm{D}_{2} \mathrm{O}(99.9$ at\% D) for NMR analysis. The ${ }^{13} \mathrm{C}$ NMR spectrum was obtained at $298 \mathrm{~K}$ on a Bruker DRX-600 NMR spectrometer (Bruker BioSpin GmbH, Germany) with TMS as an internal standard. MestReNova software (6.1.1.2.2.4) was used to count the data.

\subsection{In Vitro Enzyme Inhibition Assays}

2.7.1. Inhibition to $\alpha$-Amylase and Invertase. The activity inhibition assays to $\alpha$-amylase and invertase were measured by 3,5-dinitrosalicylic acid (DNS) [18]. The EGQK sample or positive control compound (acarbose) was added to the enzyme solution and then incubated for $10 \mathrm{~min}$ at $37^{\circ} \mathrm{C}$ or $55^{\circ} \mathrm{C}$ in $\alpha$-amylase and invertase assay, respectively. The substrate solution was added to each tube, and then the reaction was carried out at $37^{\circ} \mathrm{C}$ for $20 \mathrm{~min}$. Each tube was added with $800 \mu \mathrm{l}$ and $600 \mu \mathrm{l}$ DNS solution for $\alpha$-amylase and invertase assay, respectively. And then, the tube was heated at $100^{\circ} \mathrm{C}$ for $5 \mathrm{~min} .800 \mu \mathrm{l}$ solution in each tube was transferred to the well of the 24-well plate, and the OD value was read at $540 \mathrm{~nm}$.

2.7.2. Inhibition to $\alpha$-Glucosidase Assay. The assay of activity inhibition to $\alpha$-glucosidase was measured by $p$-nitrophenyl glucopyranoside (pNPG) [19]. In 96-well plate, the EGQK sample or acarbose was added to the enzyme solution and then incubated for $5 \mathrm{~min}$ at $37^{\circ} \mathrm{C}$. Each well was added with $20 \mu \mathrm{l}$ of $2.5 \mathrm{mM}$ pNPG solution, and then heated at $37^{\circ} \mathrm{C}$ for $30 \mathrm{~min}$. Each well was added with $80 \mu \mathrm{l}$ of $0.2 \mathrm{M} \mathrm{Na}_{2} \mathrm{CO}_{3}$ stop solution, and then the OD value was read at $405 \mathrm{~nm}$.

2.7.3. Inhibition to Lipase Assay. The activity inhibition to lipase was measured by $p$-nitrophenol (p-NPP) [20]. The EGQK sample or orlistat was added to the lipase solution and then incubated for $10 \mathrm{~min}$ at $37^{\circ} \mathrm{C}$. Each tube was added with $0.3 \mathrm{mg} / \mathrm{ml} \mathrm{p-NPP}$ solution and then incubated at $37^{\circ} \mathrm{C}$ for $30 \mathrm{~min}$. Each tube was added with $300 \mu \mathrm{l}$ of $10 \%$ trichloroacetic acid (TCA), followed with $300 \mu \mathrm{l}$ of $10 \% \mathrm{Na}_{2} \mathrm{CO}_{3}$ stop solution. $1500 \mu \mathrm{l}$ solution in each tube was transferred to the well of the 24-well plate, and the OD value was read at $405 \mathrm{~nm}$. The parameters of the indicating enzyme inhibition assay were shown in Table 1 . The enzymatic inhibitory activity was exhibited as inhibition $\%$ and was calculated as follows:

$$
\begin{aligned}
\text { Inhibition }(\%)= & \frac{\text { ODsample }- \text { ODnegtive control }}{\text { ODpositive control }- \text { ODnegtive control }} \\
& \times 100 \%
\end{aligned}
$$

\section{Results}

3.1. The Preparation Result of EGQK. The elution curve of crude $\beta$-glucan by DEAE- 52 cellulose column chromatography was shown in Figure 2. The elution peaks appeared in the 16-48 tubes, 64-78 tubes, and 96-106 tubes. The content of protein impurity was less, only appearing in the 66-84 tubes 
TABLE 1: The enzyme assay parameters.

\begin{tabular}{|c|c|c|c|c|c|c|}
\hline \multirow{2}{*}{ Enzyme assay } & \multirow{2}{*}{$\begin{array}{c}\text { Sample } \\
\text { Vol. }(\mu \mathrm{l})\end{array}$} & \multicolumn{2}{|c|}{ Substrate } & \multicolumn{2}{|c|}{ Enzyme } & \multirow{2}{*}{ Buffer $(\mathrm{pH})$} \\
\hline & & Final Conc. & Vol. $(\mu \mathrm{l})$ & Final Conc. & Vol. $(\mu \mathrm{l})$ & \\
\hline$\alpha$-Amylase & 200 & $1.5 \%$ & 400 & $0.1 \mu \mathrm{g} / \mathrm{ml}$ & 200 & Tris- $\mathrm{HCl}(\mathrm{pH} 7.0)$ \\
\hline Invertase & 200 & $50 \mathrm{mM}$ & 200 & $1 \mu \mathrm{g} / \mathrm{ml}$ & 200 & Tris- $\mathrm{HCl}(\mathrm{pH} 4.5)$ \\
\hline$\alpha$-Glucosidase & 20 & $1.25 \mathrm{mM}$ & 20 & 0.01 unit & 40 & PBS (pH 6.8) \\
\hline Lipase & 300 & $0.15 \mathrm{mg} / \mathrm{ml}$ & 600 & $1 \mathrm{mg} / \mathrm{ml}$ & 300 & Tris-HCl (pH 8.0) \\
\hline
\end{tabular}

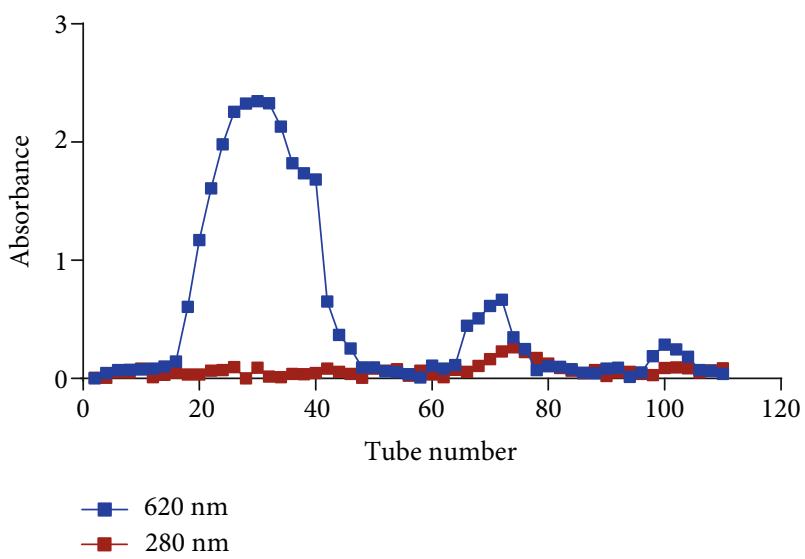

Figure 2: The elution curve of crude $\beta$-glucan by DEAE-52 cellulose column chromatography.

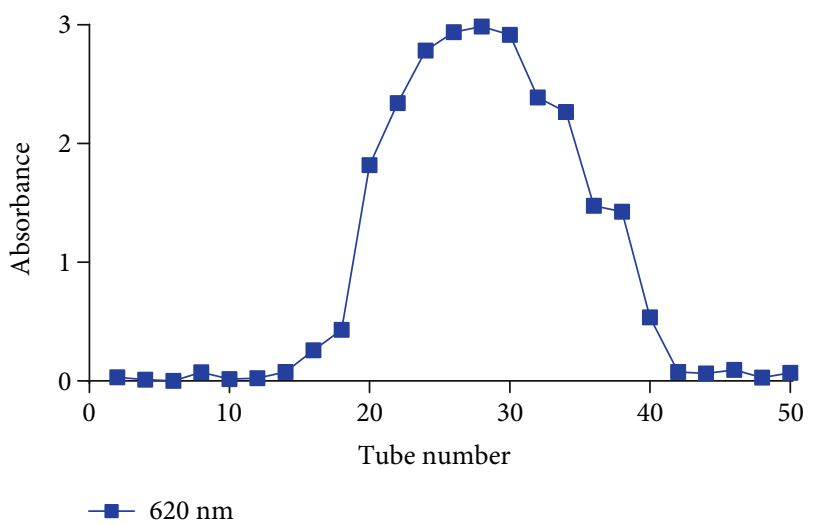

Figure 3: The elution curve of $\beta$-glucan by sepharose CL-4B agarose gel column chromatography.

with a weak absorbance and elution peak. The main sugarcontaining fractions presenting in 16-48 tubes were combined and further purified to obtain EGQK. Figure 3 showed the elution curve of EGQK by sepharose CL-4B agarose gel column chromatography, suggesting that EGQK had a uniform molecular weight. As the $\beta$-glucan was extracted and purified using this procedure, 22.8-gram $\beta$-glucan could be prepared from 1-kilogram qingke dry powder.

3.2. The Appearance and Viscosity of EGQK. EGQK showed the appearance of a light yellow powder (Figure 4). The kinematic viscosity of $0.1 \%$ solution of EGQK was $1.87 \mathrm{~mm}^{2} \cdot \mathrm{sec}^{-1}$.

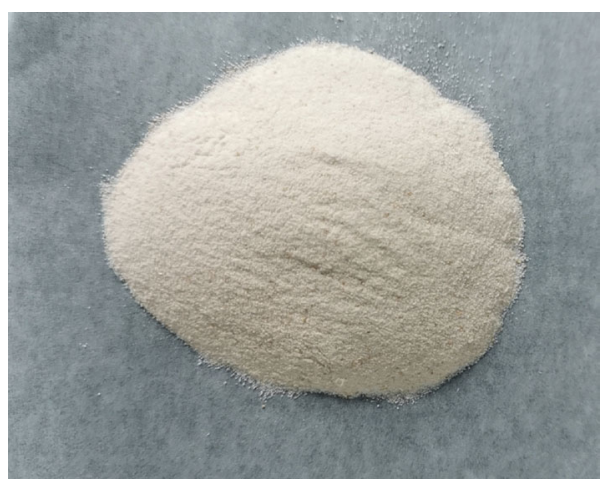

FIgURE 4: The appearance of purified enzymatic $\beta$-glucan from qingke (EGQK).

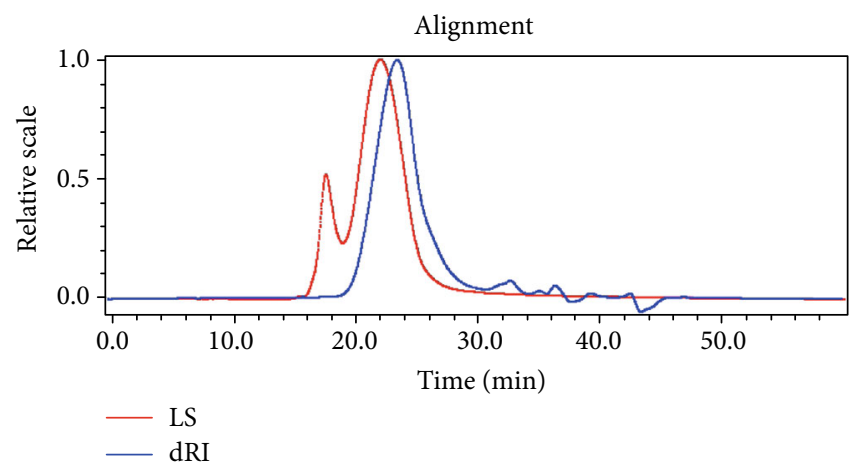

FIgURE 5: HPSEC-dRI-LS profile of the purified enzymatic $\beta$-glucan from qingke (EGQK).

3.3. Molecular Mass of EGQK. As shown in Figure 5, the HPSEC profile of EGQK was a single peak, indicating a uniform molecular weight. The molecular mass of EGQK was further analyzed and calculated by Astra software. It showed that the distribution range of the EGQK molecular weight was $201,000 \mathrm{Da}( \pm 1.323 \%)$, and the dispersion coefficient (Mw/Mn) was $1.525( \pm 2.107 \%)$.

3.4. FT-IR Characterization of EGQK. The FT-IR of EGQK (Figure 6) was assigned according to a previous report [21, 22]. Its spectral analysis revealed a wide band at 3500 $3200 \mathrm{~cm}^{-1}$ representing hydroxyl stretching vibration absorption, whereas a band at $1655 \mathrm{~cm}^{-1}$ representing its bending vibration absorption peak. Weak absorptions at 2800 $2950 \mathrm{~cm}^{-1}$ and $1350 \sim 1300 \mathrm{~cm}^{-1}$ indicated the bend and stretching vibration of a $\mathrm{C}-\mathrm{H}$. The deformation absorption 


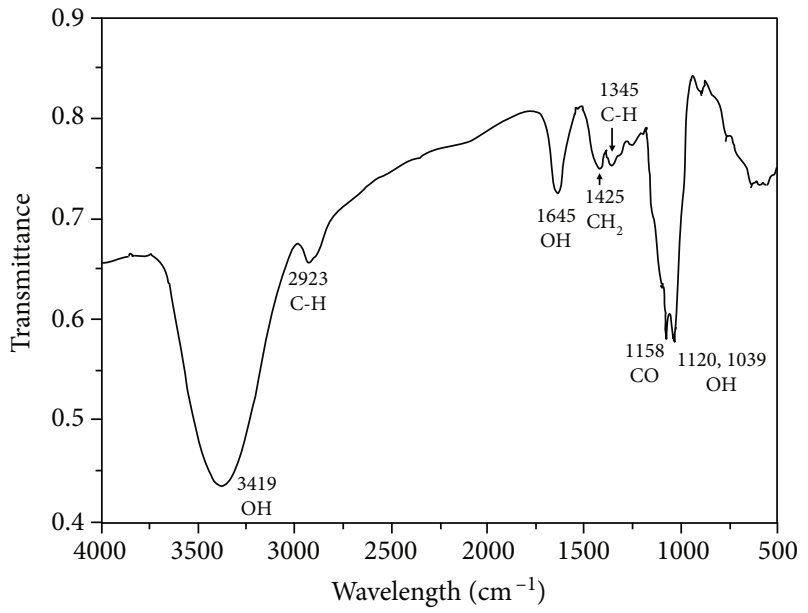

FIGURE 6: Fourier-transform infrared spectroscopy (FT-IR) spectrum of the purified enzymatic $\beta$-glucan from qingke (EGQK).

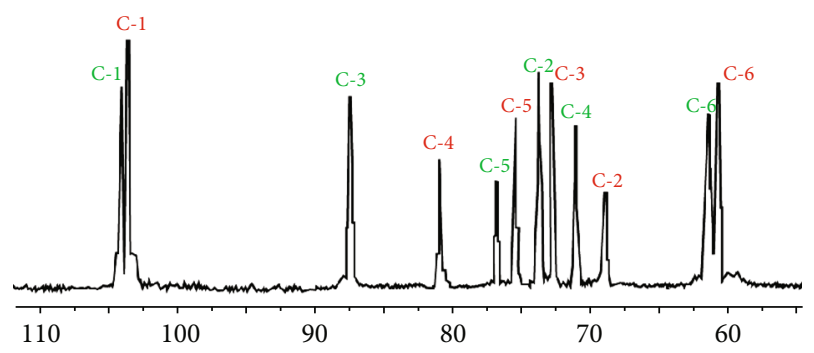

Figure 7: ${ }^{13} \mathrm{C}$ nuclear magnetic resonance (NMR) spectrum analysis of the purified enzymatic $\beta$-glucan from qingke (EGQK). $\beta-(1 \longrightarrow 4)$ is labeled red, $\beta-(1 \longrightarrow 3)$ is labeled green.

at $1425 \mathrm{~cm}^{-1}$ might indicate the presence of stretching vibrations of terminal methylene (glucose). The absorption peak at $1158 \mathrm{~cm}^{-1}$ was assigned mainly to $\mathrm{C}-\mathrm{O}$ stretching vibration on rings. The angular vibrations of alcohol hydroxyl were at both $1120 \mathrm{~cm}^{-1}$ and $1039 \mathrm{~cm}^{-1}$ with double absorption peaks.

3.5. ${ }^{13} \mathrm{C} N M R$ Analysis. ${ }^{13} \mathrm{C}$ NMR spectrum of EGQK (Figure 7) was assigned according to the previous report [23, 24]. The resonance peaks at $104.04 \mathrm{ppm}$ and $103.40 \mathrm{ppm}$ were the anomeric carbon $\mathrm{C}-1$ of $\beta$ - $(1 \longrightarrow 3)-\mathrm{D}$-glc, as well as $\beta$ $(1 \longrightarrow 4)$-D-glc $[25,26]$. The peak at $87.75 \mathrm{ppm}$ was analyzed as the C-3 carbon of the $\beta$ - $(1 \longrightarrow 3)-D-G l c$. The peaks at $73.40,71.06,76.73$, and $61.28 \mathrm{ppm}$ were the C-2, C-4, C-5, and C-6 of the $\beta$-(1 $\longrightarrow 3)-\mathrm{D}$-glc residues, respectively [24]. There were the resonances at $68.74,72.66,80.77,75.38$, and 60.71 ppm, assigned to C-2, C-3, C-4, C-5, and C-6 carbons of the $\beta$ - $(1 \longrightarrow 4)$-D-glc residue, respectively. The assignments were presented in Table 2 . The ratio of $\beta-(1 \longrightarrow 4)$ linkages and $\beta$-(1 $\longrightarrow 3)$-linkages in EGQK was approximately $3: 1$ according to the proportion of the resonance peaks of anomeric carbon (C-1) in ${ }^{13} \mathrm{C} N M R$ spectrum. As a result, we speculated that the EGQK was $\beta$-glucan. And EGQK contained some $\beta$ - $(1 \longrightarrow 3)$ linked glucose residues among the predominant $\beta$ - $(1 \longrightarrow 4)$ linked linear glucan chains.

3.6. The Enzymatic Inhibition. It was shown that in Figure 8, EGQK had certain inhibitory effects on the activities of
TABLE 2: ${ }^{13} \mathrm{C}-\mathrm{NMR}$ assigments for the purified enzymatic $\beta$-glucan from qingke (EGQK).

\begin{tabular}{lcccccc}
\hline$\beta$-Glucan & \multicolumn{6}{c}{${ }^{13}$ C-NMR chemical shifts $(\mathrm{ppm})$} \\
residue & C-1 & C-2 & C-3 & C-4 & C-5 & C-6 \\
\hline$\beta$ - $(1 \longrightarrow 3)$ & 104.04 & 73.40 & 87.75 & 71.06 & 76.73 & 61.28 \\
$\beta-(1 \longrightarrow 4)$ & 103.40 & 68.74 & 72.66 & 80.77 & 75.38 & 60.71 \\
\hline
\end{tabular}

glycosidases ( $\alpha$-glucosidase, $\alpha$-amylase, and invertase), but all of the inhibitory effects were lower than that of acarbose. All the effects exhibited a dose-dependent manner of increasing inhibition \% with the increasing EGQK concentration. EGQK presented a relatively strong inhibitory activity on $\alpha$-glucosidase. The inhibition of $\alpha$-glucosidase reached a plateau of $77 \%$ at the concentrations of $5 \mathrm{mg} / \mathrm{ml}$ and $10 \mathrm{mg} / \mathrm{ml}$. The inhibition activity of EGQK on invertase was moderate, which was similar to that of acarbose. The highest inhibition rate was around $50 \%$ at the concentrations of $6.66 \mathrm{mg} / \mathrm{ml}$ EGQK. EGQK showed a weak inhibitory effect on $\alpha$-amylase, which also had a dose-dependent manner. The inhibition rate was $25.6 \%$ by $10 \mathrm{mg} / \mathrm{ml}$ EGQK. However, EGQK did not show an inhibitory effect on lipase (data not shown). The detected inhibition \% was very low and did not present dose-dependent manner in lipase inhibition assay by EGQK, whereas the orlistat showed good dosedependent inhibition. The results suggested that EGQK has a mechanism as a hypoglycemic additive due to the inhibitory effect on glycosidases.

\section{Discussion}

$\beta$-Glucan exists in barley, oat, and wheat. It is edible and defined as a dietary fiber. There are few reports about $\beta$-glucan purification although the content of $\beta$-glucan in qingke is relatively high in cereal crops [27]. In this present study, the yield of purified and enzymatic $\beta$-glucan was $2.28 \%$. Moreover, the waste residue in the extraction and purification process generally does not contain toxic and harmful substances, thus can be reused. The physicochemical properties of the purified $\beta$-glucan were also investigated for the possible interest in food and beverage applications.

Cereal $\beta$-glucan is a type of linear glucose polymers containing oligosaccharides which are formed by the linkage of $\beta$-D-glucopyranosyl units. It is mainly linked by $\beta$ - $(1 \longrightarrow 4)$ and separated by $\beta$-(1 $\longrightarrow 3)$ [28]. In this study, by using ${ }^{13} \mathrm{C}$ NMR spectrum, it showed that EGQK possessed $\beta$-Dglucan mainly with $\beta$ - $(1 \longrightarrow 4)$-linkages and occasionally with $\beta$-(1 $\longrightarrow 3)$-linkages. The molecular weight of $\beta$-glucan is related to its viscosity. The kinematic viscosity of EGQK is relatively moderate compared to the high viscosity of the high-molecular $\beta$-glucan previously reported [16]. The viscous property expands the application into beverages.

Hull-less barley (qingke) contains a high content of $\beta$ glucan among all the cereal varieties $[29,30]$, with an average content of $5.25 \%$ and the normal content range from $4 \%$ to $8 \%$ [31]. And the content ranges of $\beta$-glucan in other barleys and oats are $2 \%-10 \%$ and $2.5 \%-6.6 \%$, respectively, which are overall lower than qingke $\beta$-glucan [32]. A new variety 


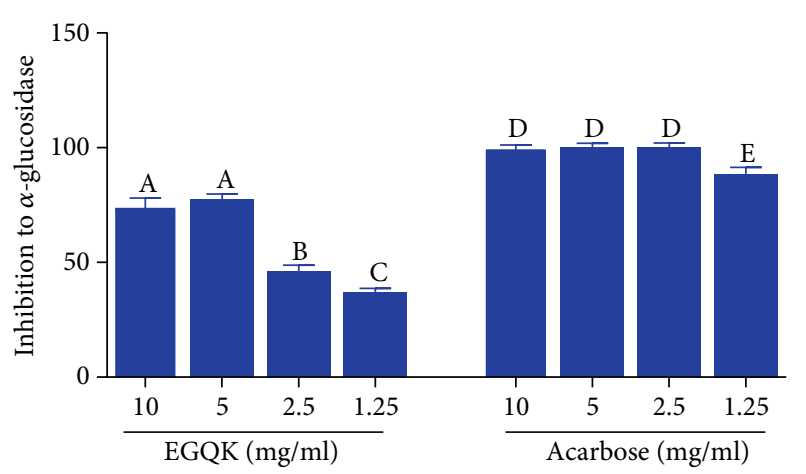

(a)

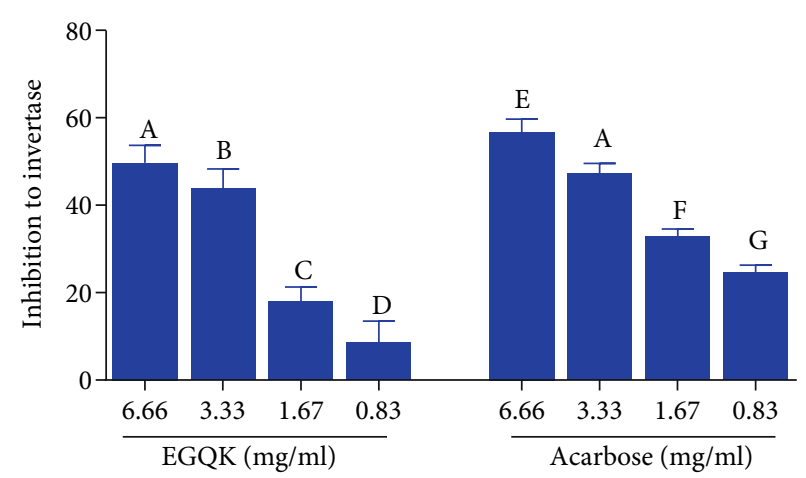

(b)



(c)

FIGURE 8: The enzymatic inhibition of the purified enzymatic $\beta$-glucan from qingke (EGQK). (a) $\alpha$-Glucosidase. (b) Invertase. (c) $\alpha$-Amylase. Bars (mean value \pm SD) with different lower case letters indicate significant differences $(p<0.05)$.

named “Zang Qing No. 25” contains $8.62 \%$ of $\beta$-glucan [33, 34]. Moreover, the bran and shorts of qingke contain more $\beta$-glucan contents (over 7\%) than reduction flours (2 3\%) and breaks $(0.8 \sim 3 \%)$ [35]. This suggests that $\beta$-glucan could be processed and utilized as functional food additives from the by-product of bran, which indicates the comprehensive usage of qingke. However, there is not much in-depth study on the characteristics of $\beta$-glucan enriching in qingke. $\beta$-glucan has multiple physiological functions $[36,37]$ including anticancer [38], clearing bowel [39, 40], regulating blood sugar [41], lowering cholesterol [42], healing wounds [43], and improving immunity [44]. As the main physiological active component of qingke, the research for $\beta$-glucan was only focused on the studies of reducing cholesterol [42] and blood sugar [41] currently. In this present study, it is the first time to explore the direct inhibitory effects of qingke $\beta$-glucan on digestive enzymes. The inhibitory effects of $\beta$ glucan on $\alpha$-glucosidase, $\alpha$-amylase, invertase, and lipase were investigated.

In Asia, the bulk of the diet is mainly starch, which metabolism involves the enzymatic hydrolysis by $\alpha$-glucosidase [45] and $\alpha$-amylase [46]. The inhibition of these two enzymes [47] is beneficial to reducing the blood sugar content $[48,49]$, preventing and treating the postprandial hyperglycemia [50, 51], and relieving the hyperinsulinemia [52, 53]. Invertase is a kind of disaccharidase hydrolyzing sucrose as a substrate. By inhibiting the absorption of sucrose in vivo, the intervention has the function of reducing blood sugar and cannot stimulate the insulin secretion by the pancreas. The results of our study showed that EGQK had a mild inhibitory effect on these enzymes, especially on $\alpha$-glucosidase. Moreover, the inhibitory effect of EGQK on invertase was similar to that by acarbose. Although the inhibitory effect of EGQK on $\alpha$-amylase was much weak, it also presented the dosedependent manner. These results could partly support the auxiliary hypoglycemic function of qingke $\beta$-glucan in vivo.

Qingke $\beta$-glucan can reduce the blood cholesterol content of experimental animals, which study is reported by Tong et al. in 2015 [42]. It confirmed that qingke $\beta$-glucan had the hypocholesterolemic effects on cholesterol metabolism in hamsters fed with hypercholesterolemic diet. And qingke $\beta$-glucan presented more inhibitory activity to 3hydroxy-3-methyl glutaryl-coenzyme A (HMG-CoA) reductase compared with oat $\beta$-glucan. Thus, the inhibitory effect of EGQK on lipase was detected in vitro in this study. However, it showed that EGQK did not inhibit lipase activity and dose-dependent manner. It speculated that the loss of lipase inhibition might be due to the enzymolysis and the reduced viscosity. But the viscosity of EGQK might perhaps be involved in the intervention on the absorption of lipid, cholesterol, and fat in digestive tract in vivo [54].

In this study, the $\beta$-glucan from qingke was isolated through cellulose column chromatography to obtain three fractions. After collecting the main fraction by agarose gel column chromatography, the EGQK has a molecular weight of $201 \mathrm{kDa}$. NMR spectroscopy indicated the preliminary structural characterization with $\beta-(1 \longrightarrow 4)$ main chain and $\beta-(1 \longrightarrow 3)$ side chain. Meanwhile, EGQK exhibited a certain inhibitory activity on $\alpha$-glucosidase, $\alpha$-amylase, and invertase and has no direct inhibitory activity on lipase. The 
preliminary study indicates that the EGQK purified from enzymatic $\beta$-glucan has the potential as natural auxiliary hypoglycemic additives in functional medicine or foods.

\section{Conflicts of Interest}

The authors declare no conflict of interest.

\section{Authors' Contributions}

Jialiang $\mathrm{Hu}$, Yue Wu and Huifang Xie contributed equally to this work.

\section{Acknowledgments}

The study was financially supported by the Jing Brand Chizhengtang Pharmaceutical Co., Ltd., for the study of "Hypoglycemic function of hull-less barley $\beta$-glucan".

\section{References}

[1] B. K. Baik and S. E. Ullrich, "Barley for food: Characteristics, improvement, and renewed interest," Journal of Cereal Science, vol. 48, no. 2, pp. 233-242, 2008.

[2] G. Zhang, W. Junmei, and C. Jinxin, "Analysis of $\beta$-glucan content in barley cultivars from different locations of China," Food Chemistry, vol. 79, no. 2, pp. 251-254, 2002.

[3] R. S. Bhatty, "The Potential of Hull-less Barley," Cereal Chemistry, vol. 76, no. 5, pp. 589-599, 1999.

[4] A. Lazaridou and C. G. Biliaderis, "Molecular aspects of cereal $\beta$-glucan functionality: Physical properties, technological applications and physiological effects," Journal of Cereal Science, vol. 46, no. 2, pp. 101-118, 2007.

[5] P. J. Wood, "Cereal $\beta$-glucans in diet and health," Journal of Cereal Science, vol. 46, no. 3, pp. 230-238, 2007.

[6] Y. Ren, H. Xie, L. Liu, D. Jia, K. Yao, and Y. Chi, "Processing and Prebiotics Characteristics of $\beta$-Glucan Extract from Highland Barley," Applied Sciences, vol. 8, no. 9, p. 1481, 2018.

[7] M. J. Tian, J. N. Song, P. P. Liu, L. H. Su, C. H. Sun, and Y. Li, "Effects of beta glucan in highland barley on blood glucose and serum lipid in high fat-induced C57 mouse," Chin J Prev Med., vol. 47, no. 1, pp. 55-58, 2013.

[8] H. Hu, P. Liu, P. P. Cheng, W. Wang, and Y. C. Liu, "Study on the auxiliary hypoglycemic function of small molecule $\beta$-glucan from Hull-less barley," Food Research and Development, vol. 39, no. 21, pp. 33-37, 2018, 99.

[9] H. Guo, S. Lin, M. Lu et al., "Characterization, in vitro binding properties, and inhibitory activity on pancreatic lipase of $\beta$ glucans from different Qingke (Tibetan hulless barley) cultivars," International Journal of Biological Macromolecules, vol. 120, pp. 2517-2522, 2018.

[10] H. Guo, K. L. Feng, J. Zhou et al., "Carboxymethylation of Qingke $\beta$-glucans and their physicochemical properties and biological activities," International Journal of Biological Macromolecules, vol. 147, pp. 200-208, 2020.

[11] H. Guo, H. Y. Li, L. Liu et al., "Effects of sulfated modification on the physicochemical properties and biological activities of $\beta$-glucans from Qingke (Tibetan hulless barley)," International Journal of Biological Macromolecules, vol. 141, pp. 41$50,2019$.
[12] H. B. I. S. C. H. O. F. F. B. AG, "Pharmacology of $\alpha$-glucosidase inhibition," European Journal of Clinical Investigation, vol. 24, no. S3, pp. 3-10.

[13] H. Chen, Q. Nie, M. Xie et al., "Protective effects of $\beta$-glucan isolated from highland barley on ethanol- induced gastric damage in rats and its benefits to mice gut conditions," Food Research International, vol. 122, pp. 157-166, 2019.

[14] G. Maheshwari, S. Sowrirajan, and B. Joseph, "Extraction and Isolation of $\beta$-Glucan from Grain Sources-A Review," Journal of Food Science, vol. 82, no. 7, pp. 1535-1545, 2017.

[15] Z. Dische, "General color reactions," Methods Carbohydr Chem, vol. 1, pp. 478-492, 1962.

[16] J. Harasym, D. Suchecka, and J. Gromadzka-Ostrowska, "Effect of size reduction by freeze-milling on processing properties of beta- glucan oat bran," Journal of Cereal Science, vol. 61, pp. 119-125, 2015.

[17] W. Cui, P. J. Wood, B. Blackwell, and J. Nikiforuk, "Physicochemical properties and structural characterization by twodimensional NMR spectroscopy of wheat $\beta$-D-glucan-comparison with other cereal $\beta$-D-glucans," Carbohydrate Polymers, vol. 41, no. 3, pp. 249-258, 2000.

[18] G. L. Miller, "Use of dinitrosalicylic acid reagent for determination of reducing sugar," Analytical Chemistry, vol. 31, no. 3, pp. 426-428, 1959.

[19] T. Satoh, A. Inoue, and T. Ojima, "Characterization of an $\alpha$ glucosidase, HdAgl, from the digestive fluid of Haliotis discus hannai," Comparative Biochemistry and Physiology. Part B, Biochemistry \& Molecular Biology, vol. 166, no. 1, pp. 15-22, 2013.

[20] S. Bendicho, M. C. Trigueros, T. Hernández, and O. Martin, "Validation and comparison of analytical methods based on the release of p-nitrophenol to determine lipase activity in milk," Journal of Dairy Science, vol. 84, no. 7, pp. 1590-1596, 2001.

[21] C. H. Xia, Q. Dai, W. Fang, and H. S. Chen, "Research on the IR Spectrscopy of Kinds of Polysaccharide," Journal Wuhan University Technology, vol. 29, no. 1, pp. 45-47, 2007.

[22] C. J. Edge, T. W. Rademacher, M. R. Wormald et al., "Fast sequencing of oligosaccharides: the reagent-array analysis method," Proceedings of the National Academy of Sciences of the United States of America, vol. 89, no. 14, pp. 6338-6342, 1992.

[23] L. Johansson, L. Virkki, S. Maunu, M. Lehto, P. Ekholm, and P. Varo, "Structural characterization of water soluble $\beta$-glucan of oat bran," Carbohydrate Polymers, vol. 42, no. 2, pp. 143$148,2000$.

[24] B. C. Lehtovaara and F. X. Gu, "Pharmacological, structural, and drug delivery properties and applications of 1,3-beta-glucans," Journal of Agricultural and Food Chemistry, vol. 59, no. 13, pp. 6813-6828, 2011.

[25] A. Idström, S. Schantz, J. Sundberg, B. F. Chmelka, P. Gatenholm, and L. Nordstierna, "13C NMR assignments of regenerated cellulose from solid-state 2D NMR spectroscopy," Carbohydrate Polymers, vol. 151, pp. 480-487, 2016.

[26] Y. Rong, N. Xu, B. Xie et al., "Sequencing analysis of $\beta$-glucan from highland barley with high performance anion exchange chromatography coupled to quadrupole time - Of - Flight mass spectrometry," Food Hydrocolloids, vol. 73, pp. 235242, 2017.

[27] B. Du, F. M. Zhu, and B. J. Xu, “ $\beta$-Glucan extraction from bran of hull-less barley by accelerated solvent extraction combined 
with response surface methodology," Journal of Cereal Science, vol. 59, no. 1, pp. 95-100, 2014.

[28] A. Cavallero, S. Empilli, F. Brighenti, and A. M. Stanca, "High $(1 \longrightarrow 3,1 \longrightarrow 4)$ - $\beta$-Glucan Barley Fractions in Bread Making and their Effects on Human Glycemic Respons," Journal of Cereal Science, vol. 36, no. 1, pp. 59-66, 2002.

[29] I. Wiege, M. Sluková, K. Vaculová, B. Panciková, and B. Wiege, "Characterization of milling fractions from new sources of barley for use in food industry," Stärke, vol. 68, no. 3-4, pp. 321-328, 2016.

[30] X. L. Zheng, L. M. Li, and Q. Wang, "Distribution and molecular characterization of $\beta$-glucans from hull-less barley bran, shorts and flour," International Journal of Molecular Sciences, vol. 12, no. 3, pp. 1563-1574, 2011.

[31] M. S. Izydorczyk, M. Jacobs, and J. E. Dexter, "Distribution and structural variation of nonstarch polysaccharides in milling fractions of hull-less barley with variable amylose content," Cereal Chemistry, vol. 80, no. 6, pp. 645-653, 2003.

[32] R. S. Bhatty, " $\beta$-Glucan and flour yield of hull-less barley," Cereal Chemistry, vol. 76, no. 2, pp. 314-315, 1999.

[33] S. F. Ma, Z. M. Diao, and B. F. Wu, "Production and Development Prospect of Qinghai Hordeum Vulgare L," Journal of Anhui Agricultural Sciences, vol. 34, no. 12, pp. 2661-2662, 2006.

[34] C. R. Dun and Y. H. Zhang, "The Scientific Practicality Technology of Using the Pesticides on Standardization Production with High Quality \& Health Care Highland Barley"Zang Qing No. 25"," Tibetan J. Agri.Sci, vol. 4, pp. 20-24, 2009.

[35] G. Šimić, D. Horvat, A. Lalić, D. Koceva Komlenić, I. Abičić, and Z. Zdunić, "Distribution of $\beta$-Glucan, Phenolic Acids, and Proteins as Functional Phytonutrients of Hull-Less Barley Grain," Foods, vol. 8, no. 12, p. 680, 2019.

[36] F. Zhu, B. Du, and B. J. Xu, "A critical review on production and industrial applications of beta-glucans," Food Hydrocolloids, vol. 52, pp. 275-288, 2016.

[37] H. Yuan, P. Lan, Y. He, C. Li, and X. Ma, "Effect of the Modifications on the Physicochemical and Biological Properties of $\beta$-Glucan-A Critical Review," Molecules, vol. 25, no. 1, p. 57.

[38] L. Mo, Y. Chen, W. Li et al., "Anti-tumor effects of $(1 \longrightarrow 3)-\beta$ d-glucan from Saccharomyces cerevisiae in S180 tumorbearing mice," International Journal of Biological Macromolecules, vol. 95, pp. 385-392, 2017.

[39] J. M. Fouhse, J. Gao, T. Vasanthan, M. Izydorczyk, A. D. Beattie, and R. T. Zijlstra, "Whole-Grain Fiber Composition Influences Site of Nutrient Digestion, Standardized Ileal Digestibility of Amino Acids, and Whole-Body Energy Utilization in Grower Pigs," The Journal of Nutrition, vol. 147, no. 1, pp. 29-36, 2017.

[40] J. M. Fouhse, M. G. Gänzle, A. D. Beattie, T. Vasanthan, and R. T. Zijlstra, "Whole-Grain Starch and Fiber Composition Modifies Ileal Flow of Nutrients and Nutrient Availability in the Hindgut, Shifting Fecal Microbial Profiles in Pigs," The Journal of Nutrition, vol. 147, no. 11, pp. 2031-2040, 2017.

[41] M. Kinner, S. Nitschko, J. Sommeregger et al., "Naked barley-Optimized recipe for pure barley bread with sufficient beta- glucan according to the EFSA health claims," Journal of Cereal Science, vol. 53, no. 2, pp. 225-230, 2011.

[42] L. T. Tong, K. Zhong, L. Liu, X. Zhou, J. Qiu, and S. Zhou, "Effects of dietary hull-less barley $\beta$-glucan on the cholesterol metabolism of hypercholesterolemic hamsters," Food Chemistry, vol. 169, pp. 344-349, 2015.

[43] N. P. Fusté, M. Guasch, P. Guillen et al., "Barley $\beta$-glucan accelerates wound healing by favoring migration versus proliferation of human dermal fibroblasts," Carbohydrate Polymers, vol. 210, pp. 389-398, 2019.

[44] Y. Ning, D. Xu, X. Zhang et al., " $\beta$-glucan restores tumoreducated dendritic cell maturation to enhance antitumor immune responses," International Journal of Cancer, vol. 138, no. 11, pp. 2713-2723, 2016.

[45] Z. Yang, X. Xu, R. Singh et al., "Effect of amyloglucosidase hydrolysis on the multi-scale supramolecular structure of corn starch," Carbohydrate Polymers, vol. 212, pp. 40-50, 2019.

[46] X. Cao, C. Zhang, Y. Dong, P. Geng, F. Bai, and G. Bai, "Modeling of cooked starch digestion process using recombinant human pancreatic $\alpha$-amylase and maltase-glucoamylase for in vitro evaluation of $\alpha$-glucosidase inhibitors," Carbohydrate Research, vol. 414, pp. 15-21, 2015.

[47] J. L. Ríos, F. Francini, and G. R. Schinella, "Natural Products for the Treatment of Type 2 Diabetes Mellitus," Planta Medica, vol. 81, no. 12/13, pp. 975-994, 2015.

[48] H. Wen, B. Tang, A. J. Stewart et al., "Erythritol Attenuates Postprandial Blood Glucose by Inhibiting $\alpha$-Glucosidase," Journal of Agricultural and Food Chemistry, vol. 66, no. 6, pp. 1401-1407, 2018.

[49] Y. Zhang, L. Luo, Z. Li, H. Li, X. Yao, and R. Luo, “Anti-Lipid Peroxidation, $\alpha$-Glucosidase and $\alpha$-Amylase Inhibitory Effects of the Extract of Capitula ofCoreopsis tinctoriaNutt. and Protection Effects on High-Fat/High-Sugar and StreptozotocinInduced Type 2 Diabetes in Mice," Chemistry \& Biodiversity, vol. 16, no. 12, p. e1900514, 2019.

[50] C. Serra-Barcellona, N. C. Habib, S. M. Honoré, S. S. Sánchez, and S. B. Genta, "Enhydrin Regulates Postprandial Hyperglycemia in Diabetic Rats by inhibition of $\alpha$-Glucosidase Activity," Plant Foods for Human Nutrition, vol. 72, no. 2, pp. 156-160, 2017.

[51] K. Rehman, T. A. Chohan, I. Waheed, Z. Gilani, and M. S. H. Akash, "Taxifolin prevents postprandial hyperglycemia by regulating the activity of $\alpha$-amylase: Evidence from an in vivo and in silico studies," Journal of Cellular Biochemistry, vol. 120, no. 1, pp. 425-438, 2019.

[52] K. Wang, L. Bao, K. Ma et al., "A novel class of $\alpha$-glucosidase and HMG-CoA reductase inhibitors from Ganoderma leucocontextum and the anti-diabetic properties of ganomycin I in KK-A y mice," European Journal of Medicinal Chemistry, vol. 127, pp. 1035-1046, 2017.

[53] C. P. Gachons and P. Breslin, "Salivary Amylase: Digestion and Metabolic Syndrome," Current Diabetes Reports, vol. 16, no. 10, p. 102, 2016.

[54] S. Leuzinger, A. Steingötter, and L. Nyström, "Viscosity of Cereal $\beta$-Glucan in the Gastrointestinal Tract," CHIMIA International Journal for Chemistry, vol. 72, no. 10, pp. 733-735, 2018. 